A C G

Rec. Nat. Prod. 16:5 (2022) 417-425

records of natural

publications

products

\title{
Secondary Metabolites with Tyrosinase and Acetylcholinesterase Inhibitory Activities from Leonuri Fructus
}

\author{
Penghua Shu $\oplus^{1}$, Yuehui Luo $\oplus^{1}$, Huiqing Zhu $\odot^{1}$, Yamin Li $\oplus^{1}$, \\ Yingying Fei $\oplus^{1}$, Mengzhu Yu $\oplus^{1}$, Ting $X u \oplus^{2}$, Yueyue Lou $\oplus^{2}$, \\ Fugang Xiao $\oplus^{1^{*}}$ and Jihong Huang $\oplus^{1^{*}}$
}

\author{
${ }^{I}$ Food and Pharmacy College, Xuchang University, Xuchang, Henan 461000, P. R. China \\ ${ }^{2}$ Institute of Microbial Engineering, Laboratory of Bioresource and Applied Microbiology, \\ School of Life Sciences, Henan University, Kaifeng, Henan 475004, P. R. China
}

(Received October 03, 2021; Revised November 17, 2021; Accepted November 19, 2021)

\begin{abstract}
Fourteen secondary metabolites, including one cinnamate derivative (1), three spirocyclic nortriterpenoids (2-4), three phenylethanoid glycosides $(\mathbf{5}-\mathbf{7})$, four lignans $(\mathbf{8}-\mathbf{1 1})$ and three phenolic compounds (12-14) were isolated from the EtOH extract of Leonuri Fructus. Their structures were elucidated on the basis of 1D NMR, 2D NMR and HR-ESI-MS data analysis. All isolates were tested for their antioxidant, tyrosinase and acetylcholinesterase inhibitory activities. Most of them showed moderate antioxidant activities. Compounds 2-4 exhibited obvious inhibitory activities against mushroom tyrosinase at $25 \mu \mathrm{M}$, with \%inhibition values of 49.36 $\pm 2.69 \%, 43.43 \pm 3.35 \%, 51.69 \pm 2.81 \%$, respectively, with arbutin used as the positive control (51.90 \pm $2.57 \%$ ). Compounds 3, 5-6 and 9-10 exhibited significant inhibitory activities against acetylcholinesterase, similar to the positive control, galantamine.
\end{abstract}

Keywords: Leonuri Fructus; Leonurus japonicus; nortriterpenoid; phenylethanoid glycoside; tyrosinase; acetylcholinesterase. (C) 2021 ACG Publications. All rights reserved.

\section{Introduction}

Leonurus japonicus Houtt. is an herbaceous flowering plant native to Asia, and its crude extract has been reported to show cardioprotective, antioxidative, anticancer, neuroprotective, analgesic, antiinflammatory, anthelminthic and antibacterial activities [1]. The air-dried ripe fruit of Leonurus japonicus Houtt, also called Leonuri Fructus, is recorded in the Pharmacopoeia of the People's Republic of China as a commonly used traditional Chinese medicine, with the effects of promoting blood circulation and regulating menstruation, clearing liver and improving eyesight [2]. So far, cyclic peptides, triterpenes, flavones and sterols have been isolated from Leonuri Fructus, which have many pharmacological effects such as antioxidation, neuroprotection, anti-inflammatory and antivirus. During the search for natural tyrosinase inhibitors from traditional Chinese medicines [3-5], the

* Corresponding author: E-Mail: xfug@163.com; Phone:086-374-2968812 Fax: 086-374-2968812

* Corresponding author: E-Mail: huangjih1216@126.com; Phone: 086-374-2968812 Fax: 086-374-2968812 
Secondary metabolites from Leonuri fructus

ethanolic extract of the Leonuri Fructus attracted our attention for its obvious inhibition activity against tyrosinase. A further investigation led to the isolation of fourteen secondary metabolites (Figure 1), three of which showed strong tyrosinase inhibitory activities, and five of the isolates exhibited obvious acetylcholinesterase inhibitory activities. Herein, the purification, characterization and bioactivities evaluation of these compounds were described.<smiles>COc1cc(COC(=O)/C=C/c2ccccc2)cc(OC)c1</smiles>

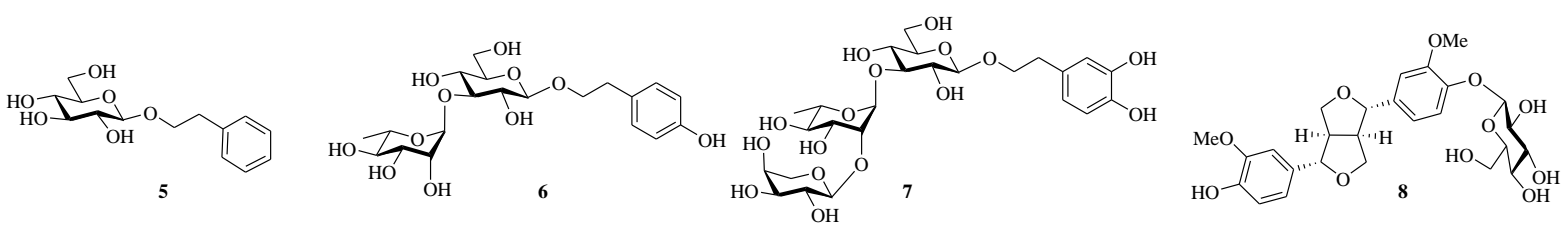

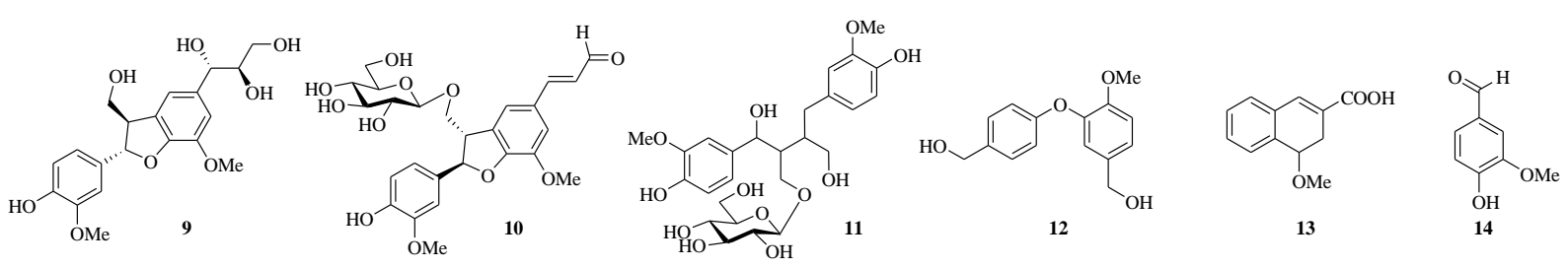

Figure 1. Chemical structures of compounds 1-14

\section{Materials and Methods}

\subsection{General Experimental Procedures}

Column chromatography (CC) was performed using silica gel (Qingdao Marine Chemical Inc., China), RP-C 18 (50 $\mu$ m, Fuji Silysia Chemical Ltd., Japan) and Sephadex LH-20 (GE Healthcare BioSciences AB, Sweden). TLC was conducted with silica gel 60 F254 (Yantai Chemical Industry Research Institute). The spots on TLC were visualized by warming $10 \% \mathrm{H}_{2} \mathrm{SO}_{4}\left(10 \% \mathrm{H}_{2} \mathrm{SO}_{4}\right.$ in ethanol) sprayed plates on a hot plate. ${ }^{1} \mathrm{D}$ and 2D NMR spectra were collected by a Bruker AM-400 spectrometer (400 MHz). UV and FT-IR spectra were determined using Puxi TU-1950 and FTIR-650 instruments, respectively. High-resolution electrospray ionization mass spectra (HR-ESI-MS) were carried out on a Bruker micrOTOF II spectrometer.

\subsection{Plant Material}

The air-dried Leonuri Fructus was collected in Yuzhou, P. R. China, in October 2020 and authenticated by Prof. Lin Yang at Lanzhou University of Technology. The specimen (SPH2020D) was stored in Food and Pharmacy College, Xuchang University.

\subsection{Extraction and Isolation}

The air-dried Leonuri Fructus $(2.0 \mathrm{~kg})$ was powdered and extracted with $95 \% \mathrm{EtOH}(3 \times 10 \mathrm{~L}$, $\left.50{ }^{\circ} \mathrm{C}\right)$. The solvent was removed at reduced pressure to yield a dark crude extract $(50.6 \mathrm{~g})$, which was suspended in $\mathrm{H}_{2} \mathrm{O}$ and extracted by $\mathrm{CH}_{2} \mathrm{Cl}_{2}$, EtOAc and $n$-BuOH. The EtOAc fraction $(10.2 \mathrm{~g})$ was subjected to silica gel CC eluting with gradients of petroleum ether-EtOAc-MeOH (20:1:0 to 0:0:1) to give ten fractions F1-F10. The fraction F2 (0.4 g, eluted by petroleum ether-EtOAc 15:1) was purified 
by CC on silica gel (petroleum ether-EtOAc 20:1 to 10:1) to give compounds $\mathbf{1}(30.5 \mathrm{mg}$ ) and $\mathbf{1 4}$ $(11.7 \mathrm{mg})$. The fraction F4 (0.3 g, eluted by petroleum ether-EtOAc 10:1) was purified by on RP-C 18 $\mathrm{CC}\left(\mathrm{MeOH}-\mathrm{H}_{2} \mathrm{O}, 40: 60\right.$ to 100:0) to afford compounds $\mathbf{1 2}(4.9 \mathrm{mg})$ and $\mathbf{1 3}(9.3 \mathrm{mg})$. The fraction F7 ( $2.1 \mathrm{~g}$, eluted by petroleum ether-EtOAc 3:1) was further separated using Sephadex LH-20 column $(\mathrm{MeOH})$ to give five subfractions $(\mathrm{F} 7-1$ to F7-5). Compounds $8(12.3 \mathrm{mg})$ and $10(10.9 \mathrm{mg})$ were gained from subfraction $\mathrm{F} 7-1$ by $\mathrm{RP}_{-} \mathrm{C}_{18} \mathrm{CC}$ using $\mathrm{MeOH}-\mathrm{H}_{2} \mathrm{O}$ (20:80 to 100:0) as eluents. Compounds $5(6.1 \mathrm{mg})$ and $9(7.7 \mathrm{mg})$ were obtained from subfraction F7-4 by Sephadex LH-20 column $(\mathrm{MeOH})$. The fraction F8 $(0.9 \mathrm{~g}$, eluted by petroleum ether-EtOAc 1:1) was passed through a $\mathrm{RP}_{-} \mathrm{C}_{18} \mathrm{CC}$ using $\mathrm{MeOH}-\mathrm{H}_{2} \mathrm{O}$ (15:85 to 100:0) as eluents to give six subfractions (F8-1 to F8-6). The subfraction F8-1 was purified on the silica gel CC to give compounds $7(13.8 \mathrm{mg})$ and $11(7.3 \mathrm{mg})$. The subfraction F8-2 was chromatographed by Sephadex LH-20 column (MeOH) to afford compound $3(9.5 \mathrm{mg})$. Compound $2(8.6 \mathrm{mg})$ was obtained from subfraction F8-3 by recrystallization with $\mathrm{MeOH}$. After further purification with Sephadex LH-20 column (MeOH), the fraction F9 gave compounds 4 (7.1 mg) and $\mathbf{6}(6.8 \mathrm{mg})$.

Compound 1. Colorless oil. IR (KBr) $v_{\max } 2956,2933,2836,1718,1639,1602,1455,1309,1253$, 1157, 1066, 977, 838, $767 \mathrm{~cm}^{-1}$. UV $\lambda_{\max }\left(\mathrm{CHCl}_{3}\right) \mathrm{nm}(\log \varepsilon): 280$ (3.5). HR-ESI-MS $\mathrm{m} / z 299.1282$ [M $+\mathrm{H}]^{+}$(calcd for $\left.\mathrm{C}_{18} \mathrm{H}_{19} \mathrm{O}_{4}, 299.1283\right) .{ }^{1} \mathrm{H}-\mathrm{NMR}\left(\mathrm{CDCl}_{3}, 400 \mathrm{MHz}\right)$ and ${ }^{13} \mathrm{C}-\mathrm{NMR}\left(\mathrm{CDCl}_{3}, 100 \mathrm{MHz}\right)$ see Table 1 .

Table 1. ${ }^{1} \mathrm{H}$ and ${ }^{13} \mathrm{C}$ NMR data of $\mathbf{1}^{\mathrm{a}}$

\begin{tabular}{llllll} 
& & & \\
\hline Position & $\boldsymbol{\delta}_{\mathbf{C}}$ & $\boldsymbol{\delta}_{\mathbf{H}}(\mathbf{m u l t}, \boldsymbol{J}, \mathbf{H z})$ & $\mathbf{p o s i t i o n}^{\prime}$ & $\boldsymbol{\delta}_{\mathbf{C}}$ & $\boldsymbol{\delta}_{\mathbf{H}}(\mathbf{m u l t}, \boldsymbol{J}, \mathbf{H z})$ \\
\hline 1 & 138.4 & & $3^{\prime}$ & 128.3 & $7.52(\mathrm{dd}, 6.4,6.4)$ \\
2 & 106.1 & $6.56(\mathrm{~d}, 2.4)$ & $4^{\prime}$ & 130.5 & $7.36(\mathrm{~m})$ \\
3 & 161.1 & & $5^{\prime}$ & 128.3 & $7.52(\mathrm{dd}, 6.4,6.4)$ \\
4 & 100.3 & $6.43(\mathrm{t}, 2.4)$ & $6^{\prime}$ & 129.0 & $6.49(\mathrm{dd}, 6.4,2.8)$ \\
5 & 161.1 & & $7^{\prime}$ & 145.4 & $7.73(\mathrm{~d}, 16.0)$ \\
6 & 106.1 & $6.56(\mathrm{~d}, 2.4)$ & $8^{\prime}$ & 117.9 & $6.49(\mathrm{~d}, 16.0)$ \\
7 & 66.4 & $5.18(\mathrm{~s})$ & $9^{\prime}$ & 166.8 & \\
$1^{\prime}$ & 134.5 & & $3-\mathrm{OMe}$ & 55.5 & $3.79(\mathrm{~s})$ \\
$2^{\prime}$ & 129.0 & $6.49(\mathrm{dd}, 6.4,2.8)$ & $5-\mathrm{OMe}$ & 55.5 & $3.79(\mathrm{~s})$ \\
\hline
\end{tabular}

a $400 \mathrm{MHz}$ for ${ }^{1} \mathrm{H}$ and $100 \mathrm{MHz}$ for ${ }^{13} \mathrm{C}$, recorded in $\mathrm{CDCl}_{3}$.

\subsection{DPPH Radical Scavenging Assay}

DPPH radical scavenging assay was conducted according to literature procedures [6], using Lascorbic acid as the positive control. All tested compounds were dissolved in DMSO. Briefly, a mixture containing $20 \mu \mathrm{L}$ of a sample solution $(1 \mathrm{mM})$ and $180 \mu \mathrm{L}$ of DPPH methanol solution $(0.2$ $\mathrm{mM}$ ) were added to 96-well microplate, which was then incubated for $30 \mathrm{~min}$ in the dark. Antioxidant activities were determined by measuring absorbances at $517 \mathrm{~nm}$ using a Multiskan FC microplate reader (Thermo Fisher Scientific, Inc.). Experiments were performed in triplicate. The DPPH radical scavenging activity was calculated by: Radical scavenging activity $(\%)=(\mathrm{Ac}-\mathrm{As}) / \mathrm{Ac} \times 100$, where Ac is the absorbance of the non-treated control and As is the absorbance of tested compound. 
Secondary metabolites from Leonuri fructus

\subsection{Acetylcholinesterase Inhibition Assay}

Acetylcholinesterase inhibition assay was conducted according to the literature procedures with slight modification [7]. Compounds 1-14 were dissolved in DMSO. A mixture containing $140 \mu \mathrm{L}$ phosphate buffer (pH 8.0), $20 \mu \mathrm{L}$ of the compound $(1 \mathrm{mg} / \mathrm{mL}), 20 \mu \mathrm{L}$ of AChE solution $(0.4 \mathrm{U} / \mathrm{ml})$ and $20 \mu \mathrm{L}$ of DTNB was added in a 96-well microplate and incubated for $15 \mathrm{~min}$ at $25^{\circ} \mathrm{C}$. The reaction was then initiated with the addition of $10 \mu \mathrm{L}$ of acetylthiocholine iodide. Hydrolysis of acetylthiocholine iodide was monitored by the formation of the yellow 5-thio-2-nitrobenzoate anion as a result of the reaction of DTNB with thiocholines, catalyzed by enzymes at $412 \mathrm{~nm}$ utilizing a 96well microplate reader. Galantamine was used as the positive control. All reactions were repeated three times. The \%inhibition was calculated as follows: \%inhibition $=(1-\mathrm{S} / \mathrm{E}) \times 100$, where $\mathrm{E}$ is the activity of enzyme without test sample and $S$ is the activity of the enzyme with test sample. The results were analyzed by program GraphPad Prism 5.0. Data are expressed as means \pm SEMs of triplicate.

\subsection{Mushroom Tyrosinase Inhibition Assay}

Mushroom tyrosinase inhibition assay was performed according to the literature procedures [8], using arbutin as the positive control. All experiments were repeated three times. The \%inhibition was calculated by $(\mathrm{Ac}-\mathrm{As}) / \mathrm{Ac} \times 100$, where As is the absorbance of tested compound and Ac the nontreated control. The results were analyzed by program GraphPad Prism 5.0. Data are expressed as means \pm SEMs of triplicate.

\section{Results and Discussion}

\subsection{Isolation and Structure Elucidation}

The air-dried Leonuri Fructus was extracted with 95\% EtOH to afford the EtOH extract, which was sequentially fractionated into $\mathrm{CH}_{2} \mathrm{Cl}_{2^{-}}$, EtOAc-, $n$ - $\mathrm{BuOH}-$ and $\mathrm{H}_{2} \mathrm{O}$-soluble fractions. The tyrosinase and acetylcholinesterase inhibitory activities were valuated among all crude extracts at a concentration of $100 \mu \mathrm{g} / \mathrm{mL}$. As shown in Table 2, the EtOAc-soluble fraction showed the strongest inhibitory activities against both tyrosinase and acetylcholinesterase. Therefore, the EtOAc-soluble fraction was chosen for further investigation on its chemical constituents in this study.

Table 2. Inhibitory activities of various fractions obtained from Leonuri Fructus on tyrosinase and acetylcholinesterase $^{\mathrm{a}}$

\begin{tabular}{ccc}
\hline Fraction & Tyrosinase inhibition (\%) & Acetylcholinesterase inhibition $(\%)$ \\
\hline Control (100\% DMSO) & $\mathrm{NI}^{\mathrm{b}}$ & $\mathrm{NI}^{\mathrm{b}}$ \\
$95 \%$ EtOH extract & $15.73 \pm 1.09$ & $23.49 \pm 0.88$ \\
$\mathrm{CH}_{2} \mathrm{Cl}_{2}$-Soluble fraction & $11.69 \pm 1.64$ & $15.66 \pm 0.95$ \\
EtOAc-Soluble fraction & $27.62 \pm 1.01$ & $36.59 \pm 0.60$ \\
$n$-BuOH-Soluble fraction & $13.71 \pm 1.50$ & $9.53 \pm 1.11$ \\
$\mathrm{H}_{2} \mathrm{O}-$ Soluble fraction & $9.88 \pm 1.12$ & $13.36 \pm 0.89$ \\
arbutin & $48.99 \pm 1.27$ & \\
galantamine $^{\mathrm{d}}$ & & $83.23 \pm 0.72$ \\
\hline
\end{tabular}

${ }^{a}$ Measured at $100 \mu \mathrm{g} / \mathrm{mL}$, results were shown as means \pm SEMs. ${ }^{\mathrm{b}}$ NI: no inhibition. ${ }^{\mathrm{c}}$ Positive control, $25 \mu \mathrm{M}$.

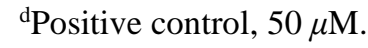


After repeated column chromatography over silica gel, RP-C18 and Sephadex LH-20, as well as recrystallization, the EtOAc-soluble fraction gave fourteen compounds (1-14), one of which was a new compound. The thirteen known ones (2-14) were identified as leonurusoleanolide A (2) [9], leonurusoleanolide J (3) [10], leonurusoleanolide D (4) [9], 2-phenylethyl $\beta$-D-glucopyranoside (5) [11], cistanoside G (6) [12], leonuriside B (7) [13], (+)-pinoresinol $O$ - $\beta$-D-glucopyranoside (8) [14], meliasendanin B (9) [15], tortoside F (10) [16], cinnacassoside A (11) [17], 4,5'-bishydroxymethyl-2'methoxydiphenylether (12) [18], eriosematin F (13) [19], 4-hydroxy-3-methoxybenzaldehyde (14) [20], respectively, by spectral comparison with literature. Compounds $\mathbf{1}$ and $\mathbf{5}-\mathbf{1 3}$ were reported from Leonuri Fructus for the first time, although compounds $\mathbf{7}$ and $\mathbf{1 4}$ have been isolated from Leonurus japonicus by Sugaya et al [21] and Zhou et al [22], respectively. The structure of the new compound (1) was identified based on extensive spectroscopic analysis as described below.

Compound 1 was obtained as a colorless oil. The molecular formula $\mathrm{C}_{18} \mathrm{H}_{18} \mathrm{O}_{4}$, with ten degrees of unsaturations, was established based on its quasi-molecular ion peak at $\mathrm{m} / \mathrm{z} 299.1282[\mathrm{M}+\mathrm{H}]^{+}$ (calcd for $\mathrm{C}_{18} \mathrm{H}_{19} \mathrm{O}_{4}, 299.1283$ ) in the HR-ESI-MS spectrum. The IR absorption band at $1718 \mathrm{~cm}^{-1}$ suggested the presence of a carbonyl group. The ${ }^{1} \mathrm{H}-\mathrm{NMR}$ spectrum of $\mathbf{1}$ revealed the signals of an $\mathrm{A}_{2} \mathrm{~B}$ spin system at $\delta_{\mathrm{H}} 6.56(2 \mathrm{H}, \mathrm{d}, J=2.4 \mathrm{~Hz}, \mathrm{H}-2, \mathrm{H}-6), 6.43(1 \mathrm{H}, \mathrm{t}, J=2.4 \mathrm{~Hz}, \mathrm{H}-4)$, suggesting the presence of one 1,3,5-tirsubstituted benzene ring. Additionally, a typical coumaroyl moiety was observed, which included a trans-double bond $\left[\delta_{\mathrm{H}} 7.73\right.$ and 6.49 (each $1 \mathrm{H}, \mathrm{d}, J=16.0 \mathrm{~Hz}, \mathrm{H}-7^{\prime}$ and H$\left.8^{\prime}\right)$ ], a benzene ring with an $\mathrm{A}_{2} \mathrm{~B}_{2} \mathrm{X}$ system $\left[\delta_{\mathrm{H}} 7.52\left(2 \mathrm{H}, \mathrm{dd}, J=6.4,6.4 \mathrm{~Hz}, \mathrm{H}-3^{\prime}, 5^{\prime}\right), 7.36(1 \mathrm{H}, \mathrm{m}, \mathrm{H}-\right.$ $\left.\left.4^{\prime}\right), 6.49\left(2 \mathrm{H}, \mathrm{dd}, J=6.4,2.8 \mathrm{~Hz}, \mathrm{H}-2^{\prime}, 6^{\prime}\right)\right]$. Apart from fifteen typical carbon signals assigned for the $1,3,5$-tirsubstituted benzene ring $\left[\delta_{\mathrm{C}} 161.1(\mathrm{C}-3, \mathrm{C}-5), 138.4(\mathrm{C}-1), 106.1(\mathrm{C}-2, \mathrm{C}-6), 100.3(\mathrm{C}-4)\right]$, and coumaroyl moiety $\left[\delta_{\mathrm{C}} 166.8\right.$ (C-9'), 145.4 (C-7'), 134.5 (C-1'), 130.5 (C-4'), 129.0 (C-2', C-6'), 128.3 (C-3', C-5'), 117.9 (C-8')], the ${ }^{13} \mathrm{C}$ and DEPT NMR spectroscopic data of $\mathbf{1}$ exhibited only three resonances attributable to two methoxy groups $\left[\delta_{\mathrm{C}} 55.5\left(3-\mathrm{OCH}_{3}, 5-\mathrm{OCH}_{3}\right)\right.$ and one methylene $\left[\delta_{\mathrm{C}}\right.$ 66.4 (C-7)]. The speculations above were confirmed by the key ${ }^{1} \mathrm{H}-{ }^{-1} \mathrm{H}$ COSY and HMBC correlations shown in Figure 2. The HMBC correlations from H-7 to C-9' showed that the connection between 1, 3, 5-tirsubstituted benzene ring and coumaroyl moiety occurred at C-7 position. The strong cross-peaks from $3-\mathrm{OCH}_{3}$ to $\mathrm{C}-3$, from $5-\mathrm{OCH}_{3}$ to $\mathrm{C}-5$ indicated that the two methoxy groups were attached to $\mathrm{C}-3$, $\mathrm{C}-5$, respectively. Therefore, the structure of compound $\mathbf{1}$ was identified as 3,5-dimethoxybenzyl cinnamate.

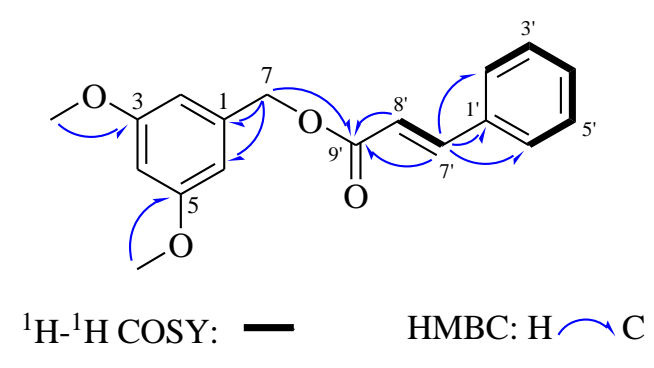

Figure 2. Key ${ }^{1} \mathrm{H}-{ }^{1} \mathrm{H}$ COSY and $\mathrm{HMBC}$ correlations for compound $\mathbf{1}$

\subsection{Antioxidant, tyrosinase and acetylcholinesterase inhibitory activities}

Compounds 1-14 were evaluated for their antioxidant activities with DPPH radical scavenging assay. As shown in Table 3, compounds $\mathbf{2}$ and $\mathbf{4}$ exhibited obvious DPPH radical scavenging activities: $57.73 \pm 1.59 \%$ for $2 ; 54.37 \pm 1.94 \%$ for $4 ; 61.41 \pm 2.74 \%$ for L-ascorbic acid (positive control). The DPPH radical scavenging activities of $\mathbf{2}$ and $\mathbf{4}$ might be ascribed to the hydroxyl substituents at their benzene rings as well as spirocyclic nortriterpenoid moieties. Besides, phenylethanoid glycosides $\mathbf{5}, \mathbf{6}$, lignans 9-11 and phenolic compound $\mathbf{1 3}$ also showed moderate antioxidant activities. 
Secondary metabolites from Leonuri fructus

Table 3. DPPH radical scavenging activity of compounds 2-7, 9-11, 13-14 and L-ascorbic acid

\begin{tabular}{cccc}
\hline Compound & $\begin{array}{c}\text { DPPH radical } \\
\text { scavenging activity }(\%)\end{array}$ & Compound & $\begin{array}{c}\text { DPPH radical scavenging } \\
\text { activity }(\boldsymbol{\%})\end{array}$ \\
\hline $\mathbf{2}$ & $57.73 \pm 1.59$ & $\mathbf{9}$ & $36.96 \pm 2.13$ \\
$\mathbf{3}$ & $21.59 \pm 2.62$ & $\mathbf{1 0}$ & $25.84 \pm 2.45$ \\
$\mathbf{4}$ & $54.37 \pm 1.94$ & $\mathbf{1 1}$ & $37.53 \pm 2.10$ \\
$\mathbf{5}$ & $31.07 \pm 2.56$ & $\mathbf{1 3}$ & $20.44 \pm 2.71$ \\
$\mathbf{6}$ & $34.51 \pm 2.33$ & $\mathbf{1 4}$ & $23.30 \pm 4.12$ \\
$\mathbf{7}$ & $27.88 \pm 2.53$ & L-ascorbic acid & $61.41 \pm 2.74$ \\
\end{tabular}

${ }^{a}$ Measured at a concentration of $1 \mathrm{mM}$. Three independent experiments were performed and results were expressed as means \pm SEMs.

At a concentration of $25 \mu \mathrm{M}$, using arbutin as the positive control, all isolated compounds were evaluated for their tyrosinase inhibitory activities. However, only the three spirocyclic nortriterpenoids 2-4 showed obvious inhibitory activities, with \%inhibition values of $49.36 \pm 2.69 \%, 43.43 \pm 3.35 \%$, $51.69 \pm 2.81 \%$, respectively, very close to the positive control arbutin $(51.90 \pm 2.57 \%)$ (Table 4$)$. Further experiments demonstrated that the $\mathrm{IC}_{50}$ values of 2-4 were also similar to that of arbutin (35.25 $\pm 0.11 \mu \mathrm{M}$ for $2,36.75 \pm 0.09 \mu \mathrm{M}$ for $3,38.72 \pm 0.13 \mu \mathrm{M}$ for $4,30.18 \pm 0.12 \mu \mathrm{M}$ for arbutin). Compounds 2-4 contain a unique 28-noroleanane-type spirocyclic skeleton. This type of compounds has been reported from many plants in the Lamiaceae family, such as Gomphostemma parviflorum [23], Notochaete hamosa [24] and Phlomis viscosa [25], and have been reported to show potent cytotoxic activities [26-27] and NGF-potentiating activity [9]. Interestingly, so far inhibitory activities against tyrosinase have not been found for 28-noroleanane-type spirocyclic triterpenoids. As the first report about their tyrosinase inhibitory activities, these results would be of great instruction to novel tyrosinase inhibitors development and medicinal value utilization of Leonuri Fructus.

Table 4. Inhibitory effects of compounds 2-4 and arbutin on mushroom tyrosinase ${ }^{\mathrm{a}}$

\begin{tabular}{ccc}
\hline Compound & Tyrosinase inhibition $(\boldsymbol{\%})$ & $\mathbf{I C}_{\mathbf{5 0}}(\mu \mathrm{M})$ \\
\hline $\mathbf{2}$ & $49.36 \pm 2.69$ & $35.25 \pm 0.11$ \\
$\mathbf{3}$ & $43.43 \pm 3.35$ & $36.75 \pm 0.09$ \\
$\mathbf{4}$ & $51.69 \pm 2.81$ & $38.72 \pm 0.13$ \\
arbutin (positive control) & $51.90 \pm 2.57$ & $30.18 \pm 0.12$ \\
\hline
\end{tabular}

${ }^{\mathrm{a}}$ Measured at $25 \mu \mathrm{M}$. Results were expressed as means \pm SEMs.

The acetylcholinesterase inhibitory effects of compounds 1-14 were evaluated, and the results were shown in Table 5. At a concentration of $50 \mu \mathrm{M}$, compounds 3, 5-6, 9-10 showed strong inhibitory activity (>55\%) against acetylcholinesterase, with \%inhibition values of $55.23 \pm 0.77 \%$, $77.79 \pm 0.47 \%, 70.29 \pm 1.21 \%, 70.89 \pm 2.05 \%, 77.02 \pm 1.51 \%$, respectively. Compounds 2 and 4 showed weak inhibitory activity, indicating that the coumaroyl moiety attached to the C-3 position might influence the acetylcholinesterase inhibitory activities of nortriterpenoids. Lignins with a benzofuran skeleton $(\mathbf{9}, \mathbf{1 0})$ showed stronger inhibitory activities than others $(\mathbf{8}, \mathbf{1 1})$. 
Table 5. Acetylcholinesterase inhibitory effects of compounds $\mathbf{3}, \mathbf{5}, \mathbf{6}, \mathbf{9}-\mathbf{1 0}$ and galantamine ${ }^{\mathrm{a}}$

\begin{tabular}{cc}
\hline Compound & Acetylcholinesterase inhibition (\%) \\
\hline $\mathbf{3}$ & $55.23 \pm 0.77$ \\
$\mathbf{5}$ & $77.79 \pm 0.47$ \\
$\mathbf{6}$ & $70.29 \pm 1.21$ \\
$\mathbf{9}$ & $70.89 \pm 2.05$ \\
$\mathbf{1 0}$ & $77.02 \pm 1.51$ \\
galantamine (positive control) & $88.85 \pm 0.69$
\end{tabular}

${ }^{a}$ Measured at $50 \mu \mathrm{M}$. Three independent experiments were performed and results were expressed as means \pm SEMs.

\section{Acknowledgments}

We thank Lanxiang Dai for the Leonuri Fructus collection and Prof. Lin Yang for the material identification. This work was financially supported by National Natural Science Foundation of China (21702178), Project of Science and Technology Department of Henan Province (212102311031), Zhongyuan Scholars in Henan (192101510004), Training Plan of Young Backbone Teachers in Universities of Henan Province (2021GGJS144), Key Scientific Research Program in Universities of Henan Province (22A350009), Undergraduate Training Program for Innovation and Entrepreneurship of Henan Province (S202110480020), the Scientific Research Innovation Team of Xuchang University (2022CXTD007), School-land Cooperation Project (980262) and Distinguished Young Scholars Fund of Xuchang University (2019).

\section{Supporting Information}

Supporting information accompanies this paper on http://www.acgpubs.org/journal/records-ofnatural-products

\section{ORCID}

Penghua Shu: 0000-0001-6018-8429

Yuehui Luo: 0000-0003-1057-0595

Huiqing Zhu: 0000-0001-5070-4856

Yamin Li: 0000-0001-8596-5765

Yingying Fei: $\underline{0000-0003-4372-9160}$

Mengzhu Yu: 0000-0001-6922-1598

Ting Xu: 0000-0001-6415-5106

Yueyue Lou: 0000-0002-7381-9290

Fugang Xiao:0000-0003-3024-6987

Jihong Huang: 0000-0002-0754-409X

\section{References}

[1] X. Shang, H. Pan, X. Wang, H. He and M. Li (2014). Leonurus japonicus Houtt.: Ethnopharmacology, phytochemistry and pharmacology of an important traditional Chinese medicine, J. Ethnopharmacol. 152, 14-32. 
Secondary metabolites from Leonuri fructus

[2] Chinese Pharmacopeia Commission (2020). Pharmacopoeia of the People's Republic of China (Vol. 1). China Medical Science Press, Beijing, pp. 252.

[3] P. Shu, L. Zhang, W. Liu, Y. Fei, M. Sun, Y. Lou, A. Liu, M. Yu, J. Li, X. Wei and N. Sun (2021). Chemical constituents from Typhonium giganteum rhizome and their antioxidant, tyrosinase inhibitory activities, Rec. Nat. Prod. 15, 53-58.

[4] P. Shu, Y. Fei, J. Li, A. Liu, L. Zhang, H. Niu, W. Liu, X. Wei, F. Xiao and Z. Xu (2020). Two new phenylethanoid glycosides from Ginkgo biloba leaves and their tyrosinase inhibitory activities, Carbohydr. Res. 494, 108059.

[5] P. Shu, M. Yu, H. Zhu, Y. Luo, Y. Li, N. Li, H. Zhang, J. Zhang, G. Liu, X. Wei and W. Yi (2021). Two new iridoid glycosides from Gardeniae Fructus, Carbohydr. Res. 501, 108259.

[6] P. Shu, J. Li, Y. Fei, H. Zhu, M. Yu, A. Liu, H. Niu, S. Zou, X. Wei, Z. Ju and Z. Xu (2020). Isolation, structure elucidation, tyrosinase inhibitory, and antioxidant evaluation of the constituents from Angelica dahurica roots, J. Nat. Med. 74, 456-462.

[7] N. Li, H.-T. Zhu, D. Wang, M. Zhang, C.-R. Yang and Y.-J. Zhang (2020). New flavoalkaloids with potent $\alpha$-glucosidase and acetylcholinesterase inhibitory activities from Yunnan black tea 'Jin-Ya', J. Agric. Food Chem. 68, 7955-7963.

[8] S. Ullah, Y. Park, C. Park, S. Lee, D. Kang, J. Yang, J. Akter, P. Chun and H.R. Moon (2019). Antioxidant, anti-tyrosinase and anti-melanogenic effects of (E)-2,3-diphenylacrylic acid derivatives, Bioorg. Med. Chem. 27, 2192-2200.

[9] Y. Liu, M. Kubo and Y. Fukuyama (2012). Spirocyclic nortriterpenoids with NGF-potentiating activity from the fruits of Leonurus heterophyllus, J. Nat. Prod. 75, 1353-1358.

[10] M. Ye, J. Xiong, J.-J. Zhu, J.-L. Hong, Y. Zhao, H. Fan, G.-X. Yang, G. Xia and J.-F. Hu (2014). Leonurusoleanolides E-J, minor spirocyclic triterpenoids from Leonurus japonicus fruits, J. Nat. Prod. 77, 178-182.

[11] J.-Y. Tan, Y. Liu, Y.-G. Cheng, Y.-P. Sun, X.-M. Li, W. Guan, J. Pan, B.-Y. Yang and H.-X. Kuang (2020). Seven new glycosides from the leaves of Datura metel L, Nat. Prod. Res. 34, 1-10.

[12] Y. Zhao, J. Zeng, Y. Liu, X. Xiao, G. Sun, J. Sun, P. Shu, D. Fu, L. Meng and Q. Wan (2018). Collective syntheses of phenylethanoid glycosides by interrupted Pummerer reaction mediated glycosylations, J. Carbohydr. Chem. 37, 471-497.

[13] X. Xiao, Y. Zhao, P. Shu, X. Zhao, Y. Liu, J. Sun, Q. Zhang, J. Zeng and Q. Wan (2016). Remote activation of disarmed thioglycosides in latent-active glycosylation via interrupted Pummerer reaction, J. Am. Chem. Soc. 138, 13402-13407.

[14] H. Kirmizibekmez, M. Erdogan, N. Kusz, N. Karaca, U. Erdem, F. Demirci and J. Hohmann (2021). Secondary metabolites from the aerial parts of Sideritis germanicopolitana and their in vitro enzyme inhibitory activities, Nat. Prod. Res. 35, 655-658.

[15] L. Wang, F. Li, C.-Y. Yang, A.-A. Khan, X. Liu and M.-K. Wang (2014). Neolignans, lignans and glycoside from the fruits of Melia toosendan, Fitoterapia 99, 92-98.

[16] B. Yi, H. Lin, M. Zhang, S. Feng, W. Xu and R. Dai (2016). Chemical constituents of Callicarpa nudiflora, Pharm. J. Chin. PLA 32, 115-119.

[17] Q. Luo, S.-M. Wang, Q. Lu, J. Luo and Y.-X. Cheng (2013). Identification of compounds from the water soluble extract of Cinnamomum cassia barks and their inhibitory effects against high-glucose-induced mesangial cells, Molecules 18, 10930-10943.

[18] D. Gamenara, E. Pandolfi, J. Saldana, L. Dominguez, M.M. Martinez and G. Seoane (2001). Nematocidal activity of natural polyphenols from Bryophytes and their derivatives, Arzneim. Forsch. 51, 506-510.

[19] W.G. Ma, Y. Fukushi, B. Ducrey, K. Hostettmann and S. Tahara (1999). Phenolic glycosides from Eriosema tuberosum, Phytochemistry 51, 1087-1093.

[20] J. Ito, F.-R. Chang, H.-K. Wang, Y.K. Park, M. Ikegaki, N. Kilgore and K.-H. Lee (2001). Anti-AIDS agents. 48. Anti-HIV activity of moronic acid derivatives and the new melliferone-related triterpenoid isolated from Brazilian propolis, J. Nat. Prod. 64, 1278-1281.

[21] K. Sugaya, F. Hashimoto, M. Ono, Y. Ito, C. Masuoka and T. Nohara (1998). Antioxidative constituents from Leonurii Herba (Leonurus japonicus), Food Sci. Technol. Int. 4, 278-281.

[22] Q.-M. Zhou, C. Peng, X.-H. Li, L. Xiong, C.-J. He, L. Guo, Z.-X. Cao and Z.-H. Liu (2013). Aromatic compounds from Leonurus japonicus Houtt, Biochem. Syst. Ecol. 51, 101-103.

[23] Q. Wang, S.-D. Luo, P. Ju and Y.-F. Wang (2007). Two novel nortriterpenoids from Gomphostemma parviflorum, Helv. Chim. Acta. 90, 1360-1365.

[24] Y. Luo, C. Feng, Y. Tian, B. Li and G. Zhang (2003). Three novel nortriterpenoids from Notochaete hamosa Benth. (Labiatae), Tetrahedron 59, 8227-8232.

[25] I. Calis, H. Kirmizibekmez, D. Tasdemir and P. Ruedi (2004). Two new triterpene and a new nortriterpene glycosides from Phlomis viscosa, Helv. Chim. Acta. 87, 611-619. 
[26] W. Peng, G. Huo, L. Zheng, Z. Xiong, X. Shi and D. Peng (2019). Two new oleanane derivatives from the fruits of Leonurus japonicus and their cytotoxic activities, J. Nat. Med. 73, 252-256.

[27] P. Liu, Z. Yao, W. Zhang, Y. Takaishi and H.-Q. Duan (2008). Novel nortriterpenes from Phlomis umbrosa, Chem. Pharm. Bull. 56, 951-955.

$$
\underset{\substack{\text { publications } \\ \text { (0) 2021 ACG Publications }}}{\text { C }}
$$

